\title{
O CONSTRUTIVISMO DE JOAQUÍN TORRES GARCÍA E SUAS PROJEÇÕES ESTÉTICAS PARA A AMÉRICA LATINA
}

\author{
CONSTRUCTIVISM JOAQUÍN TORRES GARCÍA \\ AND ITS AESTHETIC PROJECTIONS FOR A LATIN AMERICA
}

\author{
Maria Lúcia Bastos Kern ${ }^{(*)}$ \\ Pontifícia Universidade Católica do Rio Grande do Sul, \\ Porto Alegre (RS), Brasil.
}

Resumo: O presente ensaio focaliza as premissas do projeto estético para a América Latina do artista uruguaio Joaquín Torres García (1874-1949), por meio das revistas criadas por ele e seus discípulos, e as articula aos debates suscitados em distintos contextos e à sua trajetória. Aborda ainda a emergência do projeto, durante a sua estadia na Europa (1891- 1934) e após o retorno a Montevidéu (1934), onde assume a missão de difundir e consagrar o Universalismo Constructivo.

Palavras-chave: Universalismo Constructivo; Projeto Estético; Sagrado em Arte.

Abstract: This essay focuses on the assumptions of aesthetic project for Latin America of the Uruguayan artist Joaquín Torres García (1874-1949), through the magazines created by him and disciples, and articulated the debates raised in different contexts and trajectory. It also discusses the emergence of the project, during his stay in Europe (1891-1934) and after returning to Montevideo (1934), which assumes the mission to spread and consecrate Universalism Constructivo.

Key words: Universalism Constructivo; Aesthetic project; Sacred in art.

(*) Doutora, Professora titular da Pontifícia Universidade Católica do Rio Grande do Sul, do Programa de Pós-Graduação em História. E-mail:<MlKern@pucrs.br>. Recebido em: 25.10.2013, aceito em 30.11.2013. 
A modernidade vivenciada pelos artistas, nas primeiras décadas do século $\mathrm{XX}$, os estimula às experimentações de novas poéticas, às práticas de discursos em prol da autonomia da arte e do abandono da representação do mundo visível. As suas recorrentes pesquisas exigem a elaboração de textos reflexivos e estratégicos para exprimir seus pensamentos e justificar suas ideias ao público, num contato informativo direto, sem a instância da crítica de arte. O artista estabelece seu posicionamento político, no qual delimita o seu estatuto e a sua ação social. As revistas são os veículos de difusão dos conceitos, de suas obras, dos movimentos, de defesa e de combate às rejeições institucionais e do público. Elas se constituem em espaços políticos e de ação das vanguardas, de apresentação de manifestos e de projetos éticos direcionados ao futuro.

O Universalismo Constructivo de Torres García emerge após longo processo de investigação plástica e de reflexões teóricas. Desde a sua estadia em Barcelona (1891-1920), ele publica livros e artigos em revistas e jornais, nos quais expõe as suas concepções de arte, o andamento de suas pesquisas e os seus questionamentos. Nas suas obras e textos, revela o seu foco nas formas depuradas e construídas, assim como esboça a estrutura ortogonal que constituirá, mais tarde, o seu Construtivismo ${ }^{(1)}$. No entanto, é em Paris (1926-32) que este se concretiza em pinturas e objetos tridimensionais, nos quais começa a inserir símbolos de origem arcaica e de teor místico, conhecidos no Museu do Homem e em exposições de arte pré-colombiana. É nessa cidade que ele cria, juntamente com Michel Seuphor, a primeira revista, Cercle et Carré (1930-31).

Ela surge da ideia de formar um grupo de $\operatorname{artistas}^{(2)}$ e difundir a arte abstrata, em contraposição à importância que o Surrealismo assume na França. O grupo se opõe ao individualismo exacerbado e à ausência de seriedade desse movimento e projeta estabelecer a ordem diante da crise social e política europeia.

Para alguns membros do grupo Cercle et Carré, assim como para o uruguaio, o objetivo da revista é estimular o caráter espiritual da arte, enquanto outros artistas defendem a relação estreita entre arte e ciência. A revista se constitui num espaço de debate e divulgação teórica das variadas concepções de artes abstratas e construtivistas. Ela é programada para discutir os seus conceitos e pressupostos e procurar a consagração das abstrações.

Cercle et Carré congrega artistas estrangeiros que se encontram em Paris, provenientes de distintas correntes do movimento abstrato ou simpatizantes, oriundos do De Stijl, do Construtivismo, do Futurismo e da Bauhaus. Integram-se ainda ao grupo artistas provenientes do Dadaísmo, do Pós-Cubismo e os criadores do Purismo e da revista L' Esprit Nouveau (1920-1925), Ozenfant e Le Corbusier ${ }^{(3)}$, defensores de certa conotação ética em arte e de modernidade estável.

(1) O seu Construtivismo, idealismo e sua obra diferem das propostas do movimento russo.

(2) Artista uruguaio vive em Paris, após fazer a sua formação em Barcelona (1891-1920), morar em New York (1920-22), na Itália (1922-24) e criar, durante a sua estadia na capital francesa, o Construtivismo, denominado depois de retornar ao seu país de Universalismo Constructivo. Ele participa de movimentos artísticos em Barcelona e Paris, onde expõe a sua obra e publica inúmeros livros e textos, em jornais e revistas.

(3) Os primeiros membros do grupo são Torres García, Michel Seuphor, Piet Mondrian e Georges Vantongerloo; juntam-se em seguida a eles Jean Arp, Sophie Tauber, Otto Freundlich e Antoine Pevsner. Para a exposição, 46 artistas apresentaram 
A heterogeneidade de pensamentos do grupo Cercle et Carré é decorrente não apenas da origem diversificada dos artistas, mas também das múltiplas concepções relativas às artes abstratas e aos distintos campos, como pintura, escultura, arquitetura, cinema e música ${ }^{(4)}$. Enquanto alguns artistas defendem a visão espiritual de arte, portadora de uma missão ética, outros se empenham em prol da aliança arte e ciência (matemática), com ênfase na sua plasticidade pura. Ambos os grupos têm a meta de instauração da ordem. Essas soluções propostas são contemporâneas à tentativa de manutenção da arte figurativa, do gosto pelo Cubismo e da aceitação progressiva do Surrealismo.

Desde a primeira geração de artistas abstratos, o suporte teórico de suas práticas sustentava-se em concepções filosóficas projetadas para construir um novo homem, dotado de espiritualidade, porém, sem deixar de investigar novas linguagens formais. $\mathrm{Na}$ época, o debate focalizava os significados de arte abstrata, e os artistas orientavam as suas pesquisas à gramática das linhas, das cores, dos volumes e dos planos, como elementos plásticos puros.

No final dos anos de 1920, as artes abstratas ainda encontram em Paris forte resistência, apesar de sua difusão por meio de exposições e publicações. As manifestações dos artistas cubistas e pós-cubistas são as mais favorecidas pelos críticos de arte e pelas revistas especializadas por preservarem, em parte, as formas da arte nacional francesa, num momento de acentuado nacionalismo ${ }^{(5)}$.

A denominação da revista e o seu logotipo são identificados pelas formas geométricas, que simbolizam o conceito metafísico de arte, carregadas de significações a respeito do universo e do homem (SEUPHOR, 1982). O quadrado representa a ordem ambicionada pelo grupo e identifica-se com o pensamento de Torres García, que declara no texto "Vouloir construire": os artistas estão reunidos porque "reinam a desorientação e a desordem"(6). Já o círculo tem um sentido diverso e complementar ao significar, segundo Seuphor, o poder que impõe o mundo sobre ele mesmo, em rotação dinâmica. O círculo é o eterno recomeçar, é infinito ${ }^{(7)}$, e vincula-se às noções de cosmos. Nos sistemas

\footnotetext{
suas obras, podendo-se destacar Kandinsky, Léger, Prampoline, Russolo e Schwitters. Sobre os três números ( 15 março — 30 junho 1930) de Cercle et Carré vide: SEUPHOR, M. L'Art abstrait. Paris: Maeght, 1972. vol. 2; PRAT, Marie-Aline. Cercle et carré. In: Cahiers du Musée National d'Art Moderne 9, 1982. p. 109-127. SECKEL, H. La donation Seuphor. In: Cahiers du Musée d'Art Moderne 1, 1979. p. 137-141. JUIN, Hubert. Préface. In: Cercle et Carré (fac-símile). Paris: Jean Michel Place, 1977. FABRE, G. Arte abstracto, arte concreto, Cercle et Carré, Paris 1930. IVAM Centre Julio Gonzalez, 20 set.-2 dez. 1990. KARPUSZKO, K. Cercle et Carré. In: The Structurist 21/22, 1981/82. PRAT, Marie-Aline. Peinture et avant-garde au seuil des années 30. Lausanne: L'Age d'Homme, 1984.
}

(4) As divergências ideológicas permeiam as discussões diante da emergência do fascismo, do nazismo e do socialismo, apesar da meta comum em construir um mundo moderno melhor. Alguns artistas chegam à França, fugindo dos regimes totalitários instalados na Rússia, na Alemanha e na Itália, e das perseguições, motivadas por suas participações nos movimentos de vanguarda e/ou por suas condições étnicas.

(5) A revista Cahiers d'Art, dirigida por Christian Zervos, orienta os seus textos de 1929-31, no sentido de exaltar a importância do Cubismo para o desenvolvimento da arte moderna, consagrando, especialmente, Picasso e Léger. As raízes nacionais do Pós-Cubismo são valorizadas num momento de fortes nacionalismos, em que são resgatadas obras de La Tour, Poussin e Cézanne.

(6) TORRES GARCÍA, J. Vouloir construire. Cercle et Carré 1, 15 mars 1930. Segundo Seuphor, este texto foi redigido por ele, a partir de cartas escritas por Torres García.

(7) SEUPHOR, M. Autour du Cercle et Carré, op cit., p. 34. O círculo na obra de Kandinsky é a imagem do mundo e dos poderes divinos. Vide: Du spirituel dans l'art. Paris: Denoel, 1987. 
místicos, Deus é representado pelo círculo, numa esfera espiritual, enquanto o quadrado conecta-se ao mundo terrestre, humano e material.

As formas geométricas sugerem a retomada de símbolos antigos e estão relacionadas com a tentativa de descoberta da ordem do universo, concebida como mecanismo para solucionar a crise vivenciada pelos artistas, no início dos anos de $1930^{(8)}$.

As explicações de Seuphor a respeito dos significados das formas geométricas são posteriores à revista e não aparecem nos editoriais e textos da revista. Elas são distintas do primeiro editorial, no qual ele evidencia que a arte orientada ao absoluto está sendo suplantada por outra que projeta atingir a verdade. No entanto, ele delimita o conceito de construção com vistas a atingir a ordem universal e a valorizar a espiritualidade ${ }^{(9)}$, tal como pensa Torres García. A ambiguidade e a ausência de plena concordância conduz o uruguaio a romper com Seuphor e provoca o término da revista e do grupo $(1931)^{(10)}$.

Nesse momento, os objetos tridimensionais, as pinturas e os desenhos de Torres García são bem recebidos pela crítica de arte europeia. Ele continua a publicação de inúmeros textos, teóricos e reflexivos, em livros e artigos, nos quais divulga suas concepções. No entanto, a crise econômica internacional o obriga a voltar para o Uruguai (1934), onde não é sempre compreendido e legitimado pelas instituições oficiais(11).

Em Montevidéu, Torres García estabelece diferentes estratégias para se consagrar e difundir os pressupostos de seu Construtivismo. Ele faz inúmeras conferências, exposições, ministra cursos e publica artigos e vários livros, porém, sem deixar de manifestar a sua oposição às práticas artísticas locais. Diante de certo provincianismo, ele ministra cursos, forma seguidores e assume o papel de militante de vanguarda. No primeiro manifesto (1934), declara que o seu Construtivismo se constituirá numa arte coletiva e anônima, que terminará com os estatutos de autor e gênio. Além dessa provocação inicial, faz veementes críticas à arte formalista ou presa às representações simbólicas nacionais e aos conceitos românticos presentes nas concepções institucionais.

Outras estratégias são articuladas para legitimar o Construtivismo como prática artística preponderante no país, não se limitam à formação de discípulos e seguidores, mas também de colaboradores para a criação e manutenção da Associación de Arte Constructivo (AAC, 1935)(12), das revistas Círculo y Cuadrado (1936-38, 1943) e Removedor

(8) Gleizes salienta que, além da necessidade de transformação do homem e da sociedade, é de fundamental importância "a inteligência do Universal situado no sentido religioso". GLEIZES, A. Vie et mort de l'Occident Chrétien. Sablons: Moly-Sabata, 1930. p. 214.

(9) SEUPHOR, M. Pour la défense d'une architecture. In: Cercle et Carré 1, 15 mar 1930, s/p. Em depoimentos posteriores, Seuphor declara que o seu posicionamento no texto de abertura da revista é excessivamente racional, pois este tem o teor de manifesto. A diversidade de opiniões entre ele e Torres García chega a tal ponto que o primeiro modifica o texto do uruguaio, fato que gera desentendimentos e conduz Torres García a abandonar o grupo, em julho de 1930.

(10) Apenas três números da revista são publicados. O grupo se dissolve e seus membros tomam rumos distintos: Art Concret e Abstraction-Créacion.

(11) Antes de retornar ao Uruguai, ele vive em Madri, onde funda o Grupo de Arte Constructivo, faz conferências e exposições, como a mostra no Museu de Arte Moderna.

(12) Torres García projeta formar uma coletividade de artistas construtivistas, para atuar como vanguarda, desempenhar as funções apostólicas e promover mudanças sociais por meio da arte. Segundo Peluffo Linari, a AAC conta entre 1940/1 com 30 membros. PELUFFO LINARI, G. Historia de la pintura uruguaya 2. Montevidéu: Banda Oriental, 2.000. p. 74. 
(1945-53) e do Taller Torres García (1942), conhecido como Escuela Sur. Os discípulos atuam como colaboradores e militantes em prol da propagação de sua poética e de seu pensamento.

A revista Círculo y Cuadrado(13) aparece, em Montevidéu, como uma iniciativa da AAC e com o objetivo de fazer a difusão nacional e internacional do Universalismo Constructivo, denominação dada à sua arte no Uruguai ${ }^{(14)}$. Nesse momento, Torres García ministra conferências e cursos em Montevidéu e Buenos Aires sobre as novas concepções europeias de arte, em geral, similares às suas, e ao mesmo tempo expõe suas obras e escreve para o Jornal La Nación. A sua atuação se pauta num discurso cada vez mais doutrinário e persuasivo, que tem em vista liderar um grande movimento artístico em torno de suas convicções.

Os editores da revista Círculo y Cuadrado buscam dar continuidade à publicação francesa Cercle et Carré, que se constitui na segunda época e com o mesmo logotipo nos primeiros números ${ }^{(15)}$. Entretanto, a nova versão não tem a pluralidade de ideias e de debates, mas, ao contrário, é dogmática e repetitiva, como são os discursos de Torres García.

Alguns artigos são fragmentos de matérias publicadas em Cercle et Carré e revelam certa parcialidade nos recortes selecionados. É o caso, por exemplo, do artigo de Georges Vantongerloo, "Plastique", que se resume na parte introdutória do original ${ }^{(16)}$. No texto omitido, o autor sustenta as relações de arte, ciência e matemática, com que Torres García não concorda ${ }^{(17)}$. Os artigos dos artistas do grupo Cercle et Carré parecem ter o objetivo de apoiar e legitimar as ideias do uruguaio e do novo movimento num momento em que este não é ainda plenamente consagrado pela crítica de arte e pelo público de seu país. Essa dificuldade deve-se, em parte, à sua postura impositiva, intransigente e polêmica. A colaboração de artistas estrangeiros da primeira fase da revista também é estimulada para alcançar maior repercussão internacional.

No editorial do primeiro número, Torres García faz referência ao problema da dependência cultural da América Latina aos grandes centros europeus e propõe como solução a pesquisa da tradição autóctone e da arte construtiva universal, porém, com um "matiz próprio". Ele assume, claramente, sua oposição aos modernismos latino-americanos, inclusive uruguaio, fundamentados nas representações simbólicas nacionais, e enfatiza os seus ideais universal de arte e de sua integração à vida para a América Latina.

(13) A revista é publicada de maio de 1936 a setembro de 1938, e reaparece em dezembro de 1943, com 3 números (8-10) reunidos.

(14) Ele justifica a nova denominação, destacando que toda arte construtivista é fundada na doutrina e se baseia na lei de unidade, que pressupõe a existência de regra para atingir a ordem desejada. Salienta ainda que a doutrina construtivista é portadora de duplo aspecto, metafísico e artístico, bem como da tradição do homem abstrato que se constitui na "tradição da construção", do equilíbrio e da regra.

(15) Círculo y Cuadrado 1, maio de 1936, s/p.

(16) O título do texto original é "Plastique d'art (S=L2 V=L3)", que evidencia a conexão arte e ciência.

(17) Círculo y Cuadrado 4, maio de 1937. s/p. A revista publica também partes de textos de Piet Mondrian, Umberto Boccioni e A. Ozenfant em Círculo y Cuadrado 2, agosto 1936; Théo Van Doesburg, Gorin, Severini em Círculo y Cuadrado 3, fev. 1937; Henri Poincaré, Hugo Ball etc. em Círculo y Cuadrado 4, maio 1937. Do número 5 em diante, predominam as colaborações dos membros da própria Associação. 
No terceiro número do periódico, ele desenha o mapa invertido da América do Sul e o posiciona junto à linha do Equador, de tal modo que o Sul se constitui como o Norte. Com esta representação cartográfica, busca desmistificar a inexistência nesse território de tradição indígena e identificar o Norte como o novo guia das artes ocidentais. Torres García acredita que é o momento de a América do Sul se tornar o Norte, diante da fragilidade do velho continente, gerada pela crise econômica e pelos nacionalismos exacerbados $^{(18)}$.

A "ponta da América nos assinala o Norte e que estas terras tiveram tradição autóctone". Complementa: "Agora (...) temos a justa ideia de nossa posição e não como quer o resto do mundo." Entretanto, Torres García sustenta que a defesa da independência cultural não significa a ruptura com a Europa, pois tem consciência de que "aprendemos com ela e que temos muito ainda a aprender"(19).

Ele projeta a identidade cultural e a arte total para a América do Sul, assinala a importância das práticas artísticas pré-colombianas e as conecta com os conceitos de plástica, simbolismo e representação esquemática, que acredita se integrarem com os pressupostos de arte moderna internacional e com o Universalismo Constructivo ${ }^{(20)}$.

No número inaugural da revista, o uruguaio enfoca a sua concepção de arte como totalidade cósmica, como espécie de solução para a crise da arte moderna, e justifica que na tradição pré-colombiana essa concepção se encontrava integrada à espiritualidade e à vida cotidiana. Ele pensa que a arte deveria se reintegrar às suas grandes leis e se basear no concreto e nos valores plásticos puros, como outrora ${ }^{(21)}$.

Os discípulos de Torres García também difundem em artigos as suas reflexões teóricas e enfatizam pontos importantes, tais como: a geometria, que permite a construção da arte universal, em detrimento dos gênios individualistas e dos vínculos com as realidades particulares. Eles retomam os princípios construtivistas do mestre, utilizam as artes do passado como estratégia para legitimá-los e sublinham as suas metas de ordem moral e universal (SORIANO, 1938).

Nessa direção, o artigo de Luis Valcarcel publicado na revista, depois de ter aparecido no jornal La Prensa de Buenos Aires, focaliza a forma construída da arte incaica e o seu sentido ético, bem como os relaciona com as questões referenciadas múltiplas vezes por Torres García.

A leitura da revista permite observar que o mestre, os discípulos e outros seguidores comungam de modo relativamente unitário as concepções de arte e as intransigências a

(18) A ideia presente no mapa invertido já aparece em conferência realizada pelo artista na Asociación Cristiana (1935): "Disse Escola Sul porque, em realidade, nosso norte é o sul (...) e temos a justa ideia de nossa posição e não como quer o resto do mundo."

(19) Círculo y Cuadrado 3, fev. 1937. s/p.

(20) A descoberta das artes pré-colombianas por Torres García ocorre durante a estadia na Europa e nos EUA (1920-22). Ele deveria conhecer as publicações do argentino Ricardo Rojas (Erundía, 1924) e do arquiteto Angelo Guido, que enfatizam o resgate das culturas indígenas americanas para fazer frente aos problemas culturais gerados pela imigração, e os projetos de independência cultural efetuados, no México, pelos muralistas, como Diego Rivera, que conciliam as tradições pré-hispânicas e o espírito místico com a modernidade.

(21) Círculo y Cuadrado 1, maio de 1936, s/p. 
todas as práticas distintas. O caráter combativo presente nos editais e artigos de Círculo y Cuadrado não deixa de expor o pessimismo diante da pequena repercussão de suas atividades junto às instituições de arte uruguaias ${ }^{(22)}$.

As dificuldades enfrentadas para a consagração do Universalismo Constructivo não acontecem com a revista, que consegue ampla circulação internacional, principalmente nos países latino-americanos e em alguns europeus, como Espanha e França. Na Argentina, as ideias de Torres García são conhecidas por intermédio de discípulos, da coluna que mantém no jornal La Nación, de exposições e cursos. Em Buenos Aires, a sua obra é muito bem recebida ${ }^{(23)}$, fato que o estimula a lançar nesta cidade o livro Universalismo Constructivo, que tem como subtítulo: Contribuición a la unificación del arte y de la cultura de América $(1944)^{(24)}$.

Círculo y Cuadrado finaliza em setembro de 1938, e em dezembro Torres García revela a consciência de que a sua utopia não poderia se concretizar em Montevidéu. Declara no Manifiesto 2 (1938): "O Construtivismo foi. (...) Seu próprio divulgador já não se ocupa mais em insistir nas suas conferências." Justifica que a disparidade do ambiente seria o fator motivador. "Por conseguinte, tem que cessar toda a luta, e eu também com meu trabalho de explicação", mas o Construtivismo não pode desaparecer (PELUFFO LINARI, 2000). No entanto, os membros do Taller Torres García não desanimam de propagar os princípios de sua doutrina e criam outra revista, Removedor (1945-53). A nova publicação apresenta um design gráfico moderno ${ }^{(25)}$, e os artigos, de caráter pedagógico, explicam os percursos e pressupostos da arte moderna e do Construtivismo do mestre.

A revista tem maior difusão na América Latina, onde Torres García consegue fascinar outros artistas ao propor um projeto estético que concilie as tradições autóctones com o moderno. O primeiro número aparece em janeiro de 1945, quando o editor-chefe, Guido Castillo, justifica o seu nome, Removedor, e o apresenta no editorial como produto químico que extrai a tinta da tela, porém, acrescenta que também retira as concepções com as quais a obra é criada. O texto do editorial revela a animosidade dos editores, diante das práticas plásticas institucionalizadas na cidade de Montevidéu. Guido declara:

ARTISTA: você divaga em uma pintura ambígua que se constitui num só medíocre esteticismo? Aplique em suas obras REMOVEDOR abundante e de forma consciente até chegar ao fundo limpo de suas telas; mais ainda, até ao fundo de seus conceitos de Arte, e sentirá que suas obras e seus conceitos se clarificam e engrandecem. (REMOVEDOR 1,1945, p. 01.)

Removedor surge em meio a uma polêmica que repercute nos jornais, suscitada pela negação de Torres García e dos membros do Taller em apoiar as instituições de artes lo-

(22) Ver estudo sobre a revista: KERN, Maria Lúcia B. A revista Círculo y Cuadrado e a missão doutrinária de Joaquín Torres García em Montevidéu. In: Fênix, UFU On-line, p. 1-19, 2012.

(23) Ele faz exposições (1942, 1944, 1949 e 1951), ministra conferências e curso na escola de arte criada por Romero Brest, bem como colabora no primeiro número da revista Arturo, do grupo Madí.

(24) Neste livro, ele reúne em dois volumes cerca de 500 conferências proferidas após o retorno ao Uruguai.

(25) A revista apresenta um formato moderno e maior que as anteriores: $40 \mathrm{~cm}$ x $29 \mathrm{~cm}$. O primeiro número data de janeiro de 1945 e o último número, 28 de julho-agosto de 1953. 
cais e do Estado, no projeto de criação da Academia Nacional de Belas Artes. Ele justifica o fato pela ausência de afinidades de concepções de artes e pela necessidade do Taller manter fidelidade aos princípios do Universalismo Constructivo.

A publicação da revista aparece de forma irregular e conta com artigos, principalmente, de Torres García e de seus discípulos, como Guido Castillo e Sarandy Cabrera, $e$, eventualmente, de outros colaboradores ${ }^{(26)}$. Os textos de autoria de seus seguidores apresentam o caráter combativo do mestre, mas de modo mais radical, a ponto de um membro da AAC, Hector Ragni, se manifestar diante deste fenômeno. O próprio mestre publica artigos nos quais explica certos posicionamentos tomados pelos autores de Removedor e ameniza as polêmicas.

Nesse momento, os seus discursos são menos dogmáticos e mais elucidativos. Ele analisa a importância de estudar as teorias dos artistas europeus e a estrutura de suas obras em vez de imitá-los. Faz considerações a respeito de sua experiência pessoal na Europa e do acompanhamento de movimentos de vanguarda, nos quais percebe o caráter efêmero e o rápido anacronismo. Torres García acredita que o importante é estudar as teorias desses movimentos, para poder criar uma obra que seja moderna e universal. Cabe ao artista da América a missão de produzir a nova arte, que deve ser vibrante, colorida e pura plástica, sem deixar de contemplar as "regras construtivas, as cores fortes, a sonoridade e o espírito de hoje" (TORRES GARCÍA, 1946).

Conforme o artista, o genuíno no continente é o indígena, que permite com o restante das populações de imigrantes constituírem "uma civilização sui generis" e "uma nova raça criolla". Conclui: "Somos internacionais, nos faltam raízes." Esta arte deve ser universal, com espírito de hoje, porém, "cósmico. Tomando de sua sábia e profunda teogonia: Sol, Terra, Homem” (TORRES GARCÍA, 1946). Ele associa a arte moderna com as primeiras modalidades espirituais de grupos humanos, cujos rituais eram direcionados à teogonia como meios de sobrevivência.

Torres García justifica que foi a partir desses pressupostos que criou o Monumento ao Sol, no Parque Rodó, em Montevidéu, e que este é o exemplo para a nova arte da América. É "constructivo, geométrico, arquitetural, puro, abstrato", arte singular que caracteriza o homem americano como único. "Um mundo novo para o Novo Mundo" (TORRES GARCÍA, 1946). Nesse mesmo número de Removedor, ele apresenta a sua concepção de arte em caixa-alta, que ocupa a metade superior da página.

No futuro próximo a ARTE ABSTRATA terá suplantado completamente a arte imitativa; o ESQUEMA GEOMÉTRICO e as CORES PRIMÁRIAS (vão se impor face) a perspectiva e as cores compostas. Tal arte corresponderia ao Homem Novo dos povos do Novo Mundo.

Observa-se que nos discursos do artista continua recorrente a projeção utópica de instauração da nova arte para a América e de surgimento de um novo homem que integre esta à vida cotidiana, como teria sido no passado pré-colombiano.

(26) Dentre os colaboradores, destaca-se o catalão Jose Palau, como correspondente em Paris. 
Os textos mais moderados do mestre, em Removedor, ainda alimentam outras polêmicas, na medida em que o Universalismo Constructivo e as suas rigorosas premissas são criticados em Montevidéu e mesmo em Buenos Aires.

Em 1946, quando emerge a arte concreta na capital portenha, Tomás Maldonado identifica Torres García como artista eclético, cuja obra não é abstrata, em virtude da manutenção de símbolos figurativos. Arden Quin e Rod Rhotfus, discípulos do uruguaio e membros do grupo Madí, também abandonam as suas acepções rigorosas de arte, apesar de não deixarem de valorizar seus ensinamentos. Esses acontecimentos estimulam os articulistas de Removedor a retomarem o combate às obras dos artistas concretos de Buenos Aires.

Sarandy Cabrera, no artigo "Originalidad e invención", analisa os conceitos de arte desse grupo e critica o fato de se apoiar numa "arte fria, dinâmica, de espírito matemático, cerebral" (27). Ele constata que o uso da geometria na pintura não tem função plástica e nem de controle da medida harmônica, bem como critica as formas irregulares que acredita serem resultantes da necessidade de invenção e liberdade, contra a ortogonal que considera a essência do plano. O autor termina o texto com destaque a certas premissas do Universalismo Constructivo que corroboram com os motivos de sua oposição ${ }^{(28)}$.

Diante da crítica à sua obra, Torres García retoma os seus ideais de arte no artigo "El hombre, el año y la eternidad", distintos das ideias materialistas de alguns artistas argentinos. Nele, apresenta a sua concepção a respeito do estatuto de artista, como uma espécie de homem cujo ofício é praticado de modo semelhante a um religioso que tem a finalidade de criar a grande arte. A sua missão é interpretar o verdadeiro sentido da vida, pois "é o único ser capaz de captar as vibrações de um mundo superior". O objetivo do artista é atingir a perfeição e criar o "Universal: a Arte Construtiva"(29). Ele justifica o seu pensamento ao esclarecer que, desde a sua origem, a arte tem o caráter místico e sagrado.

Com o avanço da idade, Torres García focaliza em seus discursos, com maior recorrência, os temas relativos à espiritualidade e à missão sagrada da arte, mesmo tendo consciência das dificuldades que ele enfrenta. Ele tem a convicção de que o artista deve criar a sua obra a partir da realidade sensível e descobrir um sentido que se encontra nela mesma para transcendê-la. É a percepção de mundo que permite atingir tal fim. Não imitar o mundo, mas estabelecer um sentido, que nada mais é que a sua transformação e a integração do homem na "ordem do universo" (FLO, 2007).

Guido Castillo, por ocasião do lançamento do livro Mística de la pintura (1947) de Torres García e da exposição retrospectiva, revela num artigo a crença no caráter divino do mestre e da incorporação de Deus na sua obra. Portador de olhar mítico, o

(27) Torres García, no artigo "Nuestro problema de arte en América", apresenta pensamento semelhante, ao demonstrar a sua oposição à arte moderna abstrata geométrica, especialmente ao Neoplasticismo, pela frieza e caráter mecanicista. In: Removedor 14, p. 5, ago., set., out. 1946.

(28) CABRERA, S. Originalidad e invención. In: Removedor 14, p. 8 , ago., set., out., 1946. A estrutura compõe o Construtivismo do uruguaio e seus textos teóricos.

(29) TORRES GARCÍA, J. El hombre, el año y la eternidad. In: Removedor 21, p. 2-5, jan., fev., out. 1948. O autor enfatiza as premissas de seu Construtivismo, o conceito de beleza absoluta de Platão e a divina proporção. 
autor complementa que o livro é a "iniciação dos mistérios de um culto" (CASTILLO, 1947), como um meio de revelação sagrada.

Conforme o autor ${ }^{(30)}$, a sua obra, nessa época, "é realista, porque torna palpável o invisível" e pelo fato de o artista ser dotado de um "grande olho estético-metafísico que olha onde não há coisas", porém, as vê e, somente a ele, elas "se entregam como reais". Enfatiza ainda a unidade da obra e "a essência clássica" como fenômenos vivos e inéditos. A sua pintura é clássica no espírito e não na aparência externa. Ela se constitui como uma síntese do clássico, estruturada pela regra de ouro, que alia tradição ao espírito de nosso tempo.

A mística da pintura faz referência à última fase da obra de Torres García, na qual ele retoma a figuração, sobretudo, em retratos cujas formas são depuradas de detalhes e construídas. Para Guido Castillo, é uma pintura clássica, mas imprevisível. Já para Sarandy Cabrera, numa avaliação mais objetiva, ela evidencia a evolução a um novo naturalismo (CABRERA, 1947).

Observa-se que Castillo tem grande admiração pelo mestre e que nos seus textos se evidencia o pensamento idealista e a noção de criação como um fenômeno demiúrgico, que se contrapõe a alguns textos do próprio mestre, quando critica a arte local. De fato, Torres García também é detentor desse pensamento idealista, desde a sua formação em Barcelona e nos primeiros textos publicados. Ele se manifesta contra, apenas no momento que critica a arte local para impor o Construtivismo.

A revista Removedor é utilizada como veículo de consagração, divulgação das obras, das exposições individuais e coletivas, e das publicações do mestre e de seus discípulos. A publicidade é efetuada por desenhos e pictografias, bem como por textos, imagens das produções, notas em destaque e cartas.

Alguns artigos de Torres García analisam as lições ministradas e revelam de modo didático as etapas de seu método de formação de artistas, o qual é amplamente apreciado por colegas e críticos de arte estrangeiros, e motivo de recorrentes visitas à Escuela Sur.

Ele esclarece que, ao longo de sua trajetória, trabalha numa acepção de arte mais ampla, sem estabelecer hierarquias entre arte maior e menor, sempre conectando as tradições estéticas e místicas pré-colombianas com o universal, o clássico e o moderno.

A obra e os textos de Torres García evidenciam o seu pensamento idealista e sua missão para impor a ordem e a espiritualidade por meio de sua obra artística. As revistas, desde Cercle et Carré até aquelas criadas pelo artista e pela AAC, em Montevidéu, tiveram a finalidade de difundir, diretamente ao público, os conceitos teóricos e as práticas de seu Construtivismo e de estabelecer novos estatutos de arte e artista, num contexto provinciano em que estas questões não são admitidas. Procura ainda suplantar o problema da identidade nacional, recorrente entre os movimentos modernistas latino-americanos, com o projeto estético, no qual a arte deveria se integrar à vida e, no futuro, todos os homens seriam artistas.

(30) CAStillo, G. Mística de la pintura en la exposición de Torres García. In: Removedor 17, p. 5, março, abril, maio 1947. Para Torres García, a arte clássica é sempre construtiva, sendo mais construtiva do que a representação. "Lección primera del Taller Torres García." In: Removedor 23, p. 1, abril 1949. A sua pintura continua sendo estruturada pela construção formal e pela síntese. 
Depois da morte de Torres García (1949), Removedor continua ainda sendo publicada e a Escuela Sur forma novas gerações de artistas, segundo seus métodos didáticos e suas concepções de arte total. Os discípulos, ao prosseguirem a divulgação de sua obra e promoverem exposições nacionais e internacionais, colaboram para atingir a ambicionada consagração no Uruguai e no exterior.

Torres García consegue concretizar a constituição da coletividade de artistas construtivistas em Montevidéu, sobretudo após a sua morte. Assim, a missão apostólica assumida pelo mestre do Universalismo Constructivo, com a constante militância, por meio de mais de quinhentas conferências, textos em revistas e livros, bem como de exposições no país e no exterior, somados à qualidade da obra, são fundamentais para o seu reconhecimento. A sua intransigência diante da diversidade de concepções e os recorrentes conflitos, desde o grupo e a revista Cercle et Carré, dificultam e retardam o processo de legitimação, principalmente, pelas divergências com artistas em Montevidéu.

As revistas e os textos uruguaios permitem verificar que a sua missão não se condiciona ao seu país, mas à independência da arte e das sociedades latino-americanas em face dos grandes centros cosmopolitas, num momento de fragilidade em que estes vivenciam a grande crise econômica e a Segunda Guerra Mundial.

\section{BIBLIOGRAFIA}

FABRE, Gladys. Arte abstracto, arte concreto. Cercle et Carré, Paris 1930. IVAM. Centre Julio Gonzalez, set./dez., 1990.

GLEIZES, A. Vie et mort de l'Occident Chrétien. Sablons: Moly-Sabata, 1930.

KANDINSKY, Wassily. Du spirituel dans l'art. Paris: Denoel, 1987.

KARPUSZKO, K. Cercle et Carré. In: The Structurist 21/22, 1981/82.

KERN, Maria Lúcia B. A revista Círculo y Cuadrado e a missão doutrinária de Joaquín Torres García em Montevidéu. In: Fênix, UFU On-line, p. 1-19, 2012.

PELUFFO LINARI, Gabriel. Historia de la pintura uruguaya 2. Montevidéu: Banda Oriental, 2.000. PRAT, Marie-Aline. Cercle et carré. In: Cahiers du Musée National d'Art Moderne 9, p. 109-127, 1982.

PRAT, Marie-Aline. Peinture et avant-garde au seuil des années 30. Lausanne: LAge d'Homme, 1984.

Revista Cercle et Carré, 1930. Fac-simile, Paris: Editions Jean-Michel Place, 1977.

Revista Círculo y Cuadrado, Associación de Arte Constructivo, 1936-38; 1948.

Revista Removedor, Taller Torres García, 1945-1953.

SECKEL, H. La donation Seuphor. In: Cahiers du Musée d'Art Moderne 1, p. 137-141, 1979.

SEUPHOR, Michel. L'Art abstrait. Paris: Maeght, 1972. vol. 2.

SEUPHOR, Michel. Autour du Cercle et Carré. Nantes: Convergence, 1982.

TORRES GARCÍA, Joaquín. New York, Montevidéu: Fundação Torres García, 2007.

TORRES GARCÍA, Joaquín. Universalismo Constructivo. Contribuición a la unificación del arte y de la cultura de América. Madri: Alianza Editorial, 1984. 